\title{
Geodynamic monitoring and its maintenance using modeling by numerical and similar materials methods
}

\author{
Konstantin Morozov ${ }^{1 *}$, Arkady Shabarov ${ }^{1}$, Anton Kuranov ${ }^{1}$, Nikita Belyakov', Boris \\ Zuyev $^{1}$, Dmitriy Vlasenko ${ }^{1}$, Dmitriy Demekhin ${ }^{1}$, Eugene Bakhtin ${ }^{1}$ \\ ${ }^{1}$ Research center of Geomechanics and issues of mining industry, St. Petersburg Mining University, \\ St. Petersburg, Russia
}

\begin{abstract}
The paper describes the fundamental issues of deformation monitoring systems and instrumental methods for measuring the stressstrain state of the rock massif based on the use of three-component strain sensors developed by specialists from the University of Mines and Avangard OJSC.

One of the main tasks of the developed systems is the prediction and prevention of possible dynamic manifestations of rock pressure in rockburst-hazardous deposits.

KEYWORDS: stresses, strains, deformations, displacements, threecomponent strain sensors, rock bursts, deformation monitoring systems, stress field measurements, mining safety.
\end{abstract}

\section{INTRODUCTION}

Modern mining enterprises are extremely interested in estimating of the initial stress field in the rock massif, in actual determination of the stress distribution around the underground excavations and in monitoring of the deformation processes in the host rock massif. In most cases, the parameters of the stress-strain state (SSS) are predicted on the basis of numerical modeling of stress fields. Actual numerical models of deposits require the results of field studies of the SSS assessment, which are based on the measurement of deformations (deformation monitoring) of the rock massif during mining operations.

Deformation monitoring seems to be the most promising system that allows in conjunction with data from other types of monitoring to give a reliable picture of the distribution of stresses in the rock massif and to approach the solution of a number of pressing practical issues of mining production (for example the issue of prediction of rock bursts). At the same time for today in Russia deformation monitoring of the SSS of the rock massif remains virtually unfulfilled [1].

Since 2011 specialists of St. Petersburg Mining University and Avangard OJSC [2,3] have been working on the development of deformation monitoring systems (SMD) to predict dangerous geodynamic phenomena during underground mines excavation at Russian mining enterprises. A key component of both the SMD and the instrumental

\footnotetext{
${ }^{*}$ Corresponding author: morozov_kv@pers.spmi.ru
} 
complex for estimating the SSS of a rock massif is a three-component strain sensor. Many scientific publications are devoted to the geodynamic monitoring [4,5,6,7,8,9,10,11,12].

The article discusses the design features of three-component strain sensors and two technologies based on the use of sensor data:

- deformation monitoring systems;

- modified method for estimating SSS using ring unloading.

\section{METHODS}

\subsection{Deformation Monitoring System (SMD)}

The main idea of deformation monitoring is to determine the extreme deformations in critical areas of the rock massif (for example: pillars, roofs, intersections of mines) corresponding to the stresses at which potential energy accumulates and this energy can be realized in the form of dynamic manifestations of rock pressure (for example rock bursts).

The choice of deformations as a measured parameter is due to the fact that we cannot conduct direct measurements of the stresses in the rock massif. The transition from deformations to the magnitude of the stresses is carried out using the apparatus of the continuum mechanics theory.

These statements formed the basis of the methodology for determining the impact hazard [13] developing started from 2015 by specialists from St. Petersburg Mining University. The technique is based on the results of the deformation control of the state of the rock massif which is carried out using the deformation monitoring system (SMD). A key component of the SMD is a three-component strain sensor, developed jointly with Avangard OJSC [3].

The sensor allows recording of deformations in the rock massif and dynamic movements of structural blocks simultaneously in three orthogonal directions.

In addition to the sensor the SMD includes: a complex of recording equipment for collecting, processing and transmitting information from three-component sensors; specialized software "Monitoring SMD"; auxiliary equipment (communication and power cables, batteries, etc.).

The image of the last version of the sensor DD-3.2 (2018) with two additional axes located at angles of $45^{\circ}$ to the principal axes is shown in Figure 1. The main technical characteristics of the sensor are shown in Table 1.

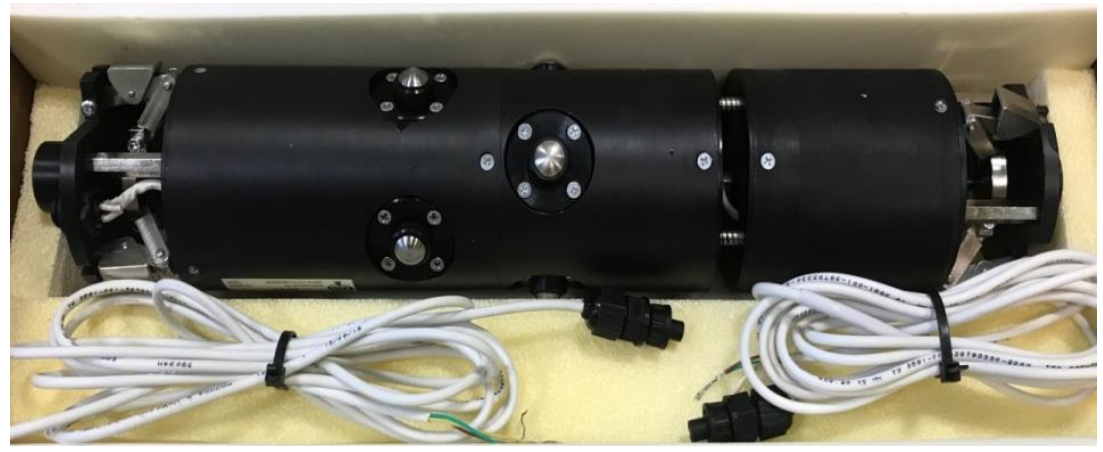

Fig. 1. Improved strain sensor (DD-3.2).

Sensors are installed at critical mining areas (pillars, roofs, intersections of mines) in horizontal boreholes with the following parameters: 
- height of the borehole head from the underground excavation bottom is 1.3-1.5 m;

- diameter of borehole is from 76 to $79 \mathrm{~mm}$;

- installation depth of sensors is at least two relative linear dimensions (diameters) of underground excavation.

Table 1. Technical characteristics of the sensor DD-3.2

\begin{tabular}{|l|c|}
\hline Basic parameter, unit & Parameter value \\
\hline Measuring range of displacements along the axes X, Y, & 8 \\
XY, YX, Z, $\mu \mathrm{m}$ & 10 \\
\hline Resolution of measuring of displacements with axes X, & \\
Y, XY, YX, Z, $\mu \mathrm{m}$ & $-5 . .+20$ \\
\hline Ambient temperature range, ${ }^{\circ} \mathrm{C}$ & $30 . .95$ \\
Relative air humidity, $\%$ & 12 \\
\hline Sensor supply voltage, $\mathrm{V}$ & 2 \\
Power consumption by one sensor, no more than, $\mathrm{W}$ & $0 . .15$ \\
\hline Depth of sensor installation in the borehole, $\mathrm{m}$ & No more 73 \\
Outer diameter of the sensor, mm & Not less than IP67 \\
\hline Shell protection &
\end{tabular}

The method of observation provides for continuous operation of sensors, data lines and remote access systems. The readings of the sensors are carried out with a minimum interval of $1 \mathrm{~min}$. The maximum interval is set by the operator of the SMD and should not exceed 2 hours.

\subsection{Estimation of the SSS of the rock massif by improved method of ring unloading (IMRU)}

IMRU is based on the use of the characteristics of the elastic recovery of the studied part of the massif in case of artificial violation of its connection with the main massif. The principal difference of the method from other unloading methods is the measurement of deformations with the help of a multi-component strain sensor with complete unloading of rocks of the studied area.

The IMRU technique involves measuring the deformations of the borehole walls that occur when the host rock massif is unloaded by an annular gap. High-precision strain sensors DD-3.1 are used as measuring equipment. Sensors under consideration make it possible to determine the deformations of the walls of a measuring borehole with an accuracy of $10 \mu \mathrm{m}$.

In the host rock massif, the measurement boreholes are drilled with a diameter of $82 \mathrm{~mm}$. To perform the correct installation of the sensor and protect it from mechanical damage when it is moved while unloading part of the rock massif, the main condition is to completely place the sensor in a prepared measuring borehole. In addition, the actual drilling of the measuring borehole is influenced by the actual mining and geological conditions at the measurement site (the presence of open cracks, the thickness of the sprayconcrete lining, etc.). The measuring borehole is drilled to a depth of at least $300 \mathrm{~mm}$. In the borehole the sensor is installed close to the face of borehole. To create rock massif unloading zone around the borehole with a sensor installed by the method of drilling, an annular gap with a diameter of at least $132 \mathrm{~mm}$, a width of $4 \mathrm{~mm}$ and a depth of more than $280 \mathrm{~mm}$ is performed. The installed measuring equipment records the resulting deformations of the borehole walls during unloading of the rock massif. 
The equipment necessary for carrying out ring unloading includes: strain sensors for measuring rock deformations when unloading rock massif, drilling equipment and a diesel generator to provide electrical power to the drilling rig. Processing of the results of field studies is carried out using specialized software and empirical-analytical dependencies obtained by the result of numerical modeling.

\section{RESULTS}

\subsection{Deformation Monitoring System (SMD)}

We had the first experience of creating a deformation monitoring system (SMD) in 20112013 at the Glubokiy mine of the Antey deposit in the Trans-Baikal Territory [14].

The deposit includes steeply dipping vein-stockwork uranium ores at depths of up to $800 \mathrm{~m}$. The deposit is characterized by a combination of factors of structural heterogeneity and physical and mechanical properties of rocks, as well as violation of the natural stress state of the rock massif. All these factors in combination with technological impact lead to increasing of the risk of dynamic phenomena manifestations occurrence that adversely affect the safety of mining operations. Prior to the introduction of the SMD a system of regional seismic-acoustic monitoring was already functioning at the mine enterprise. The creation of the SMD made it possible to monitor the state of the rock massif in the local most dangerous areas of mining operations.

The basis of the SMD are deformation stations or pavilions (DS). The deformation stations of the system are located in the horizons of the mine in the places of the expected dynamic manifestations of rock pressure.

The deformation pavilion is an isolated niche from which three pairs of orthogonal boreholes have been drilled along the lines of action of the principal normal stresses. The length of the boreholes is selected with taking into account the condition of the measuring base placement (end of the boreholes) outward the zones of influence of underground excavation. The size of these zones is about 2-3 relative diameters of underground excavation. In our case the length of the boreholes in the pair were 5 and $8 \mathrm{~m}$ and the measuring base was $3 \mathrm{~m}$. The scheme of boreholes placement in the DS is shown in Figure 2 (A).

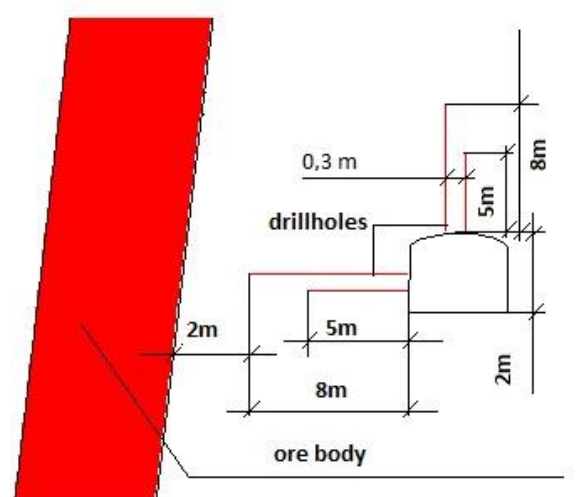

A.

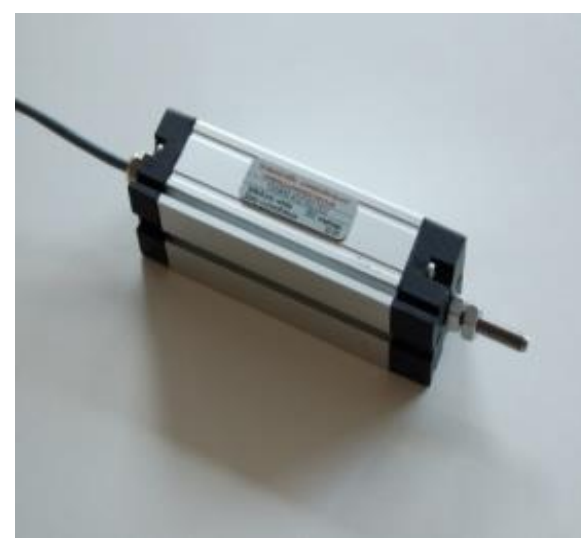

B. 


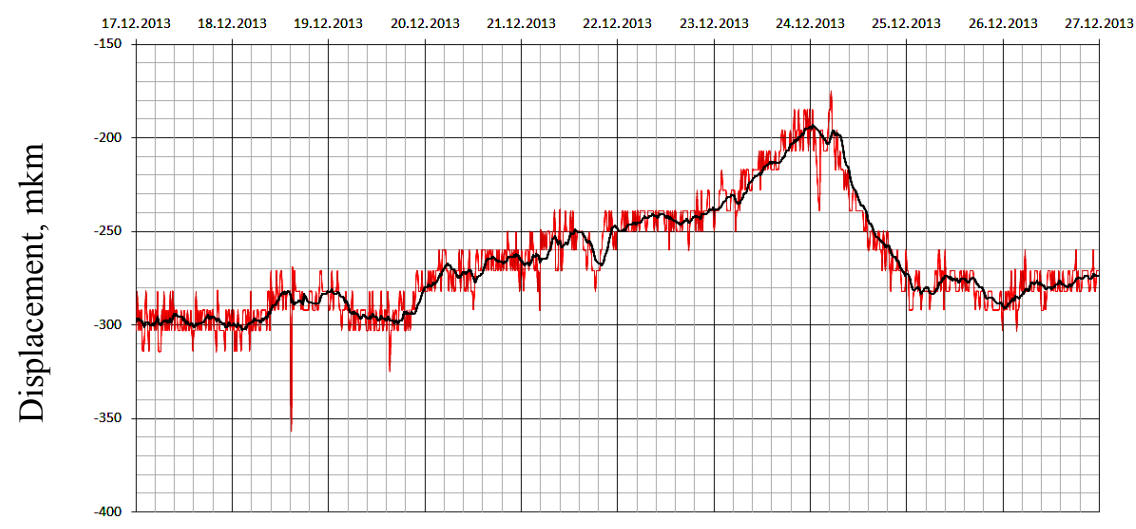

C.

A - boreholes placement; B - potentiometric displacement sensor MMS33-K-50-IP «Megotron»; C - Example of monitoring results graph;

Fig. 2. Scheme of the deformation detection station [3].

To automate the process of polling sensors, collecting, storing and organizing data access, specialized software has been developed $[2,11]$. The system is monitored remotely. The monitoring results are available both at the workplace of the operator of the mining site and in the laboratory of the Scientific Center in St. Petersburg. Data can be presented in tabular or graphical form.

The results of a retrospective analysis of literature data and data of numerical modeling $[2,15]$ of rock bursts events showed that the burst-dangerous state of rocks occurs when the value of relative normal deformations $\varepsilon_{1}=(3.5-7.1) \cdot 10^{-3}$ and $\varepsilon_{3}=(1.2-4.3) 10^{-3}$ at depths from 650 to $300 \mathrm{~m}$.

The dependence of the displacements at a three-meter base (compression deformations) from the depth is shown in Figure 3. With increase of depth the critical compression deformations decrease according to a linear law. It should be noted that we are talking about the full values of deformations without reference to the load rate of the rock massif.

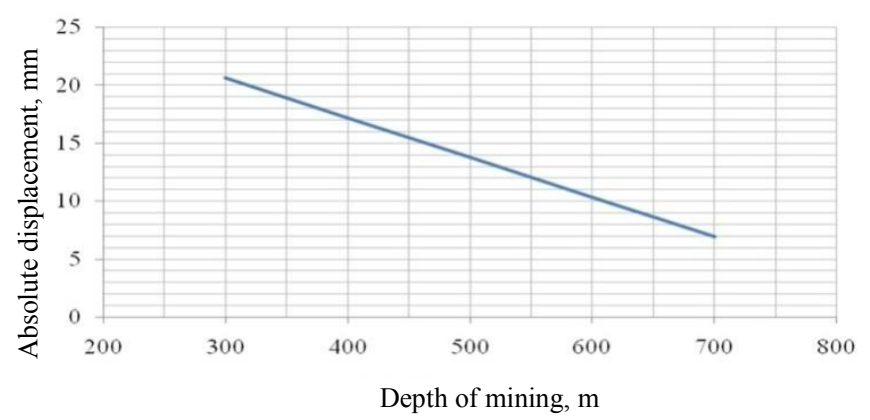

Fig. 3. The predicted value of the accumulated deformation of the rock massif corresponding to the dynamic manifestations of rock pressure [2].

The main drawback of the considered SMD is the laborious and expensive process of building and equipment of the SDM pavilions with the need to drill niches to allocate the boreholes, drill three pairs of orthogonal boreholes and install deep bench marks.

All this predetermined the need to develop a new sensor design and methodology for the construction of SMD, allowing to:

- abandon the construction of niches; 
- measure three components of deformations at one point (borehole) instead of drilling three pairs of boreholes;

- combine a bench mark and a sensor which makes it possible to abandon the installation of long (5-10 m) bench marks in each borehole.

All this will significantly simplify the process of deployment of the SMD in all underground excavations which are dangerous for possible dynamic manifestations of rock pressure.

\subsection{Estimation of the SSS of the rock massif by improved method of ring unloading (IMRU)}

Ring unloading modelling was performed by the finite-elements method. The principal geometry of the model is shown in Figure 4.

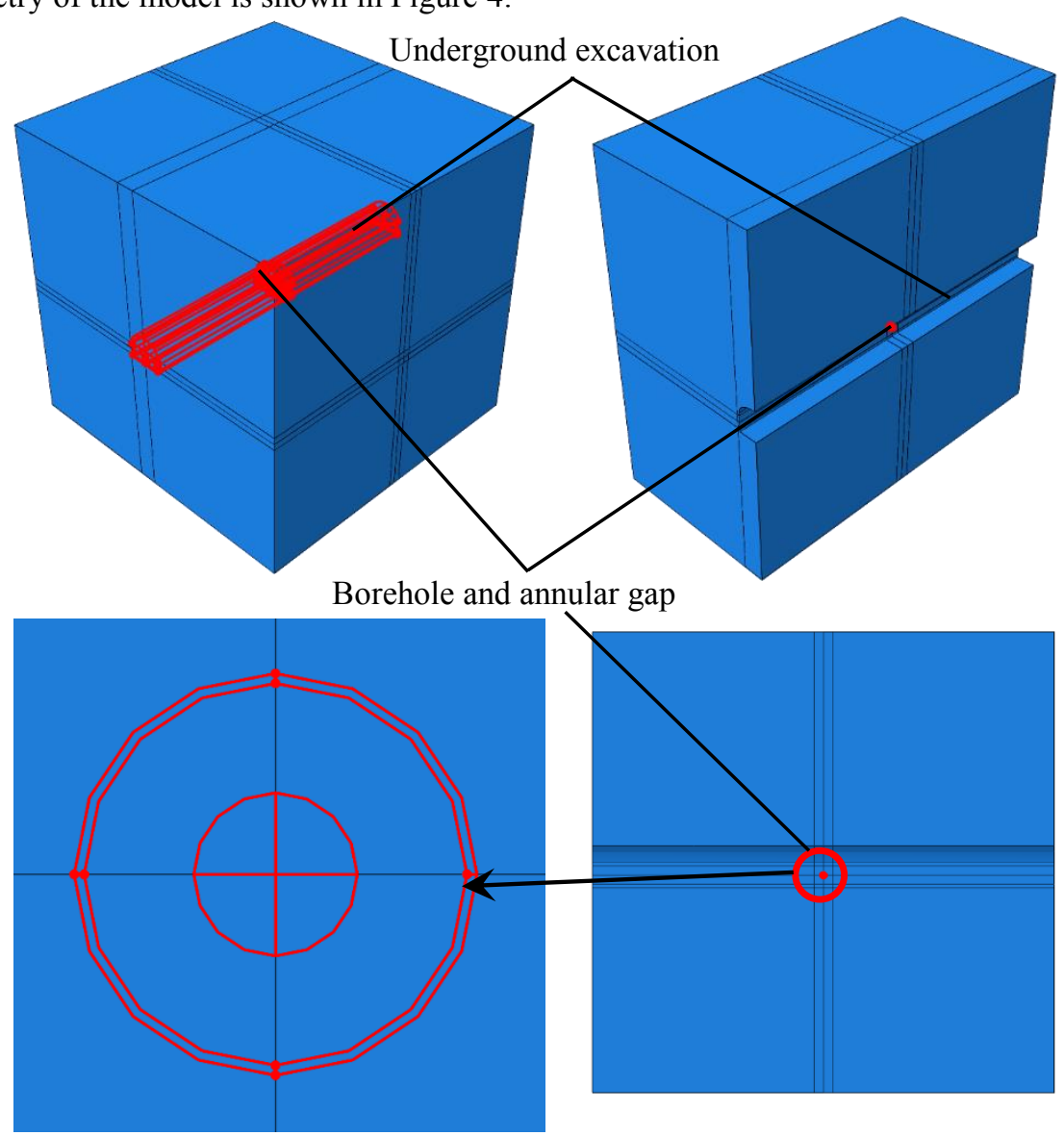

Fig. 4. Design scheme of finite-element model.

The numerical model involved the following design steps:

1. the formation of the initial stress state in the host rock massif;

2. excavation of underground working;

3. drilling of the primary borehole;

4. the formation of the unloading annular gap. 
The main task of the modeling was the selection of such parameters of the initial stress state which would provide the displacements of the walls of the primary borehole after the creation of a unloading annular gap corresponding to the field measurements. In this case, it can be assumed that precisely such parameters of the initial (natural) stresses acted in the host rock massif before the start of mining operations.

It should be noted that since the boreholes and annular gaps are located in the side of the underground excavations then only two of the three principal components of the natural stress field will affect the magnitude of the displacement of the wall of the borehole during unloading. Moreover, for drifts these are the vertical and horizontal along the strike of ore body principal stresses components, and for crosscuts these are the vertical and horizontal across the strike of ore body principal stresses components.

The method of determining the natural stresses on the basis of multivariate modeling of ring unloading and field observations can be summarized as follows:

1. It is necessary to carry out field measurements of the displacements of the borehole walls during its unloading by an annular gap in mutually perpendicular excavations (drifts and crosscuts);

2. It is necessary to perform a modeling of a ring unloading using numerical methods for mutually perpendicular excavations. During multivariate modeling we should change the ratio and the absolute values of the components of rock massif natural stresses;

3. Based on multivariate modeling, it is necessary to establish the pattern of changes in the borehole walls displacements when it is unloaded by an annular gap on the ratio and absolute values of natural stresses, and then to perform an approximation of the obtained dependence by the most appropriate type of functional dependence.

4. In the obtained approximating dependencies of the natural stresses components on the components of the borehole walls displacements during unloading the annular gap, it is necessary to substitute the displacements values measured in field conditions and determine the values of natural stresses.

An example of the dependence of the components of the natural stresses field on the displacements of the borehole walls when unloading the annular gap for drifts is shown in Figure 5.

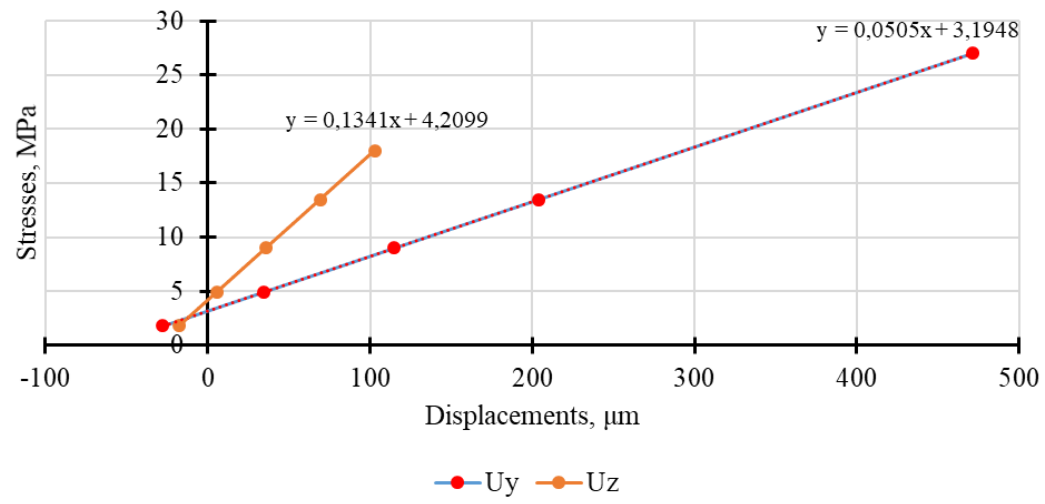

Fig. 5. Graphic dependences of the principal components of natural stresses on the displacements of the borehole walls during unloading by the annular gap. Uy - vertical displacement; Uz - horizontal displacement along the excavation axis.

As can be seen from the obtained graphical dependencies they are linear and are exactly approximated by the corresponding linear laws. This is due to the applied mathematical model of the rock massif (linear elastic body) and means that the obtained approximating dependencies will be valid beyond the limits of the considered values of stresses. 
Numerical modeling is performed within the framework of continuum mechanics and cannot give a picture of the deformation of the borehole walls during the development of rock destruction processes. In this regard, in some cases it is advisable to carry out a solution of a similar problem using the method of physical modeling on equivalent materials.

An example of the processing of research results for one of the objects of JSC "Polymetal" is given in Table 2.

Table 2. Calculated parameters of the natural stress state

\begin{tabular}{|l|l|l|l|l|l|}
\hline № & Measurement location & $\mathrm{Uy}, \mu \mathrm{m}$ & $\mathrm{Uz}, \mu \mathrm{m}$ & $\sigma \mathrm{y}, \mathrm{MPa}$ & $\sigma \mathrm{z}, \mathrm{MPa}$ \\
\hline 1 & Point $1 .+285 \mathrm{~m}$ & 398 & 391 & 23,29 & 56,64 \\
\hline 2 & Point $2,+285 \mathrm{~m}$ & 159 & 47 & 11,22 & 10,51 \\
\hline 3 & Point 3,+285 m & 242 & 82 & 15,42 & 15,21 \\
\hline 4 & Point 4, +270 m & 72 & 161 & 6,83 & 25,80 \\
\hline 5 & Point $6,+270 \mathrm{~m}$ & 189 & 1,5 & 12,74 & 4,41 \\
\hline 6 & Point $8,+255 \mathrm{~m}$ & 407 & 517 & 23,75 & 73,54 \\
\hline 7 & Point $10,+215 \mathrm{~m}$ & 426 & 404 & 24,71 & 58,39 \\
\hline
\end{tabular}

Analyzing the data in the table, it should be noted that the results of the determination of natural stresses in the rock massif have a significant variation, which is undoubtedly associated with an equally significant variation in the boreholes contour shifts measured under natural conditions during unloading.

\section{DISCUSSION}

\subsection{Deformation Monitoring System (SMD)}

An example of the presentation of monitoring results in graphical form is shown in Figure 6.

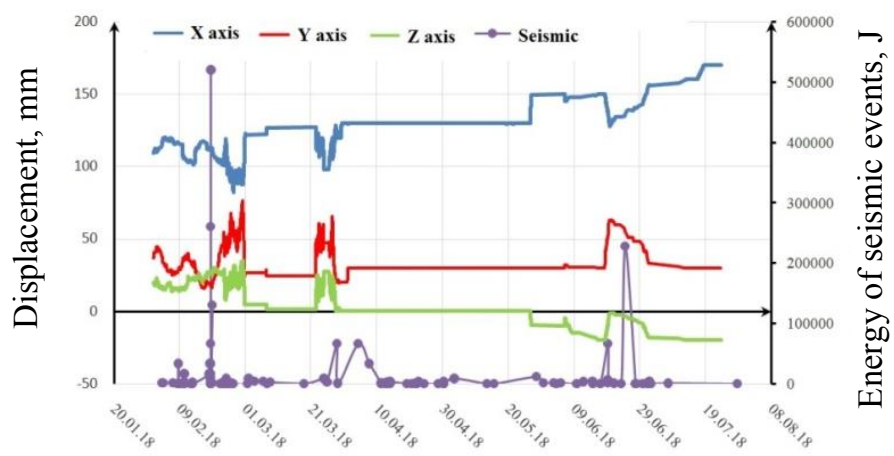

Date

Fig. 6. Results of strain monitoring by sensor No 6 taking into account seismic events associated with the maximum increase in deformations.

Assessing the general nature of the deformation, it can be concluded that the deformations along the two main axes (X, Y) pass in opposite directions, i.e. when stretched along one axis, synchronous compression of the other occurs, which indicates the prevailing action of stresses in one direction, in this case, along the horizontal. The deformations along the $\mathrm{Z}$ axis largely coincide with those described above, but they are 
distinguished by smaller values of deformations (no more than $25 \mu \mathrm{m}$ ) and the predominance of compression deformation in the general trend.

To establish the correlation of deformations with seismic events the data of seismic events near the location of the sensors was analyzed. Seismic events with a maximum energy within a radius of $100 \mathrm{~m}$ from the sensor were recorded at the time of the realization of maximum deformations along all three axes.

It should be particularly noted that the seismic occurrence of the order of $10^{5}$ was preceded by a period of deformation change within a few days. The presence of such a period can be used as one of the prognostic features in a comprehensive analysis of data from seismic-deformation monitoring.

Furthermore, besides technical features the most important characteristic of a SMD is the criteria (threshold values) of rock massif deformations indicating the onset of a state in which dynamic manifestations of rock pressure are possible.

To date, a wide range of studies have been conducted in the field of numerical and physical modeling in order to determine the relationship between the stresses and well deformations of the borehole walls. The results are presented in Figure 7. The criteria values of deformations corresponding to the destruction of the massif were obtained for typical conditions of mining of apatite-nepheline deposits: uniaxial compressive strength for ore is $80 \mathrm{MPa}$ and for rocks is $120 \mathrm{MPa}$; the sensors are outside the zone of influence of underground excavations in the area of compression with a ratio of maximal and minimal principal stresses equal to $2: 1$.

From the results of the modeling it follows that up to displacement values of $300 \mu \mathrm{m}$ for the ore massif and $350 \mu \mathrm{m}$ for the rock massif linear law of dependency of stresses and strains is observed. A further increase in stresses is accompanied by nonlinear deformations up to a complete loss of stability at deformation values of $950 \mu \mathrm{m}$.

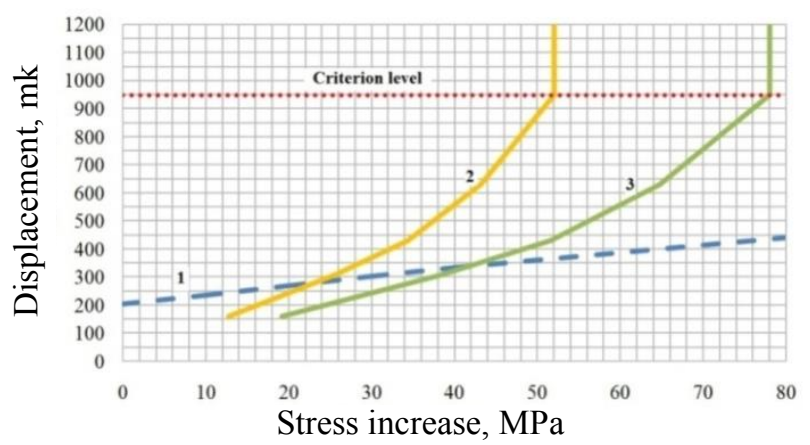

Fig. 7. Comparative analysis of borehole deformation on a physical model and numerical simulation. 1 - Numerical simulation results (elastic deformation); 2 - The results of physical modeling for the ore massif; 3 - Results of physical modeling for rock massif.

It should be noted that the destruction at this magnitude of deformations can proceed quite quickly which makes it possible at the moment to recommend these deformation values as a criterion of impact rock burst hazard.

In the future according to the data accumulated during the operation of the SMD the range of influencing factors in the experiments can be increased. Comparative analysis of this data will be used to expand the methodology and set of criteria for transition from displacements of boreholes walls which characterizing the strain state of the rock massif to its stress state parameters. In addition, there is the possibility of using additional criteria such as the rate of growth (decline) of deformations in connection with seismic data, a complex indicator that takes into account the results of local and regional monitoring. 


\subsection{Estimation of the SSS of the rock massif by improved method of ring unloading (IMRU)}

Empirical and analytical dependencies are obtained for the averaged deformation properties of a rock massif. When performing recalculations of borehole wall displacements during unloading into natural stresses a correction factor should be taken into account. This factor reflects the difference in the actual deformation properties of the rock massif with averaged values applied during multivariate modeling.

Accounting for structural disturbance of the rock massif is performed by introducing an amendment of the actual deformation properties of rocks obtained on core samples to the deformation properties of the massif with allowance for structural disturbance according to rating systems.

The presented method will be further adjusted according to the experience of the work taking into account the introduction of elements into the sensor design to measure the borehole contour displacements, which make it possible to measure shear strains. Accounting for the shear strains will require the introduction of additional relationships to determine the shear stresses in the area in which the shear strains will be measured. Thus, it will be possible to fully determine the components of the stresses tensor at the measurement points, as well as to find the magnitudes and directions of the principal stresses corresponding to the natural stress state of the rock massif.

\section{CONCLUSIONS}

The proposed construction of a three-component strain sensor allows to obtain the full strains tensor at critical points in the rock massif.

Three-component strain sensors, communication lines, data processing and transmission servers along with established criteria and developed software constitute the core of the deformation monitoring system. The constructed deformation monitoring systems control the deformation of the rock massif and substantially complement the results of seismic monitoring of the geodynamic situation, increasing safety and efficiency (no emergency situations) of mining operations during the development of rock bursts hazardous deposits.

The use of the developed three-component sensors made it possible to create a methodology for estimating the SSS of rock massif by an improved method of unloading. The method allows to significantly simplify the process of testing and increase the reliability of the estimates of rock massif natural stress state. At present, the method is undergoing pilot tests in conditions of mining enterprises in Russia.

\section{REFERENCES}

1. A.N. Shabarov, S.V. Tsirel, K.V. Morozov, I.Yu. Rasskazov, Mining Journal, The concept of integrated geodynamic monitoring in underground mining, № 9, p.p. 59-64, (2017).

2. K.V. Morozov, S.V. Tsirel, A.A. Kuranov, St. Petersburg Mining University. Proceedings of the VII International Scientific and Practical Conference «Innovative directions in the design of mining 
enterprises», Monitoring of rock mass deformations around the workings as part of a system for predicting dynamic phenomena during mining of hazardous deposits, p.p.358-363, (2017).

3. A.E. Pushkarev, K.V. Morozov, F.V. Molev, St. Petersburg offers, The system of geomechanical monitoring of the stress-strain state of an array of rocks based on three-component displacement sensors, № 1 (24), p.p. 48-50, (2017).

4. M.A. Guzev, I.Y. Rasskazov, G.S. Tsitsiashvili, Procedia Engineering, Algorithm of Potentially Burst-hazard Zones Dynamics Representation in Massif of Rocks by Results of Seismic-acoustic Monitoring, vol. 191, p.p. 36-42, (2017).

5. I.Yu. Rasskazov, B.G. Saksin, V.I. Usikov, M.I. Potapchuk, Gornyi Zhurnal, Rock mass geodynamics and mining-induced rockbursting at Nikolaev complex deposit, №12.

6. Lan Tianwei, Zhang Hongwei, A.S. Batugin, Li Sheng, Han Junm, Cao Bo, Zhou Xinwei, Geomechanics and Geodynamics of Rock Masses - Selected Papers from the 2018 European Rock Mechanics Symposium, Discussion on dynamical system of rockburst under tectonic stress field in coal mine, (2018).

7. V.D. Baryshnikov, V.G. Kachalsky, D.V. Baryshnikov, IOP Conference Series: Earth and Environmental Science, Upgrading the multi-component borehole strainmeter for the accuracy improvement of stress measurement in rocks, vol. 134, (2018).

8. T.V. Lobanov, V.A. Kvochin, V.K. Klimko, Interexpo Geo-Siberia, Deformation monitoring of stress accumulation processes to control the shock hazard of the array during the development of the Tashtagol field, p.p. 148-153, (2005).

9. Guidelines for the field of mining operations in the fields of prone and dangerous for rock bursts (Khibiny apatite-nepheline deposits), Apatity-Kirovsk: AO Aptait, 112 p., (2016).

10. V. Vladimirov, A. Mikhailov, F. Molev, A. Sergushev, Electronics: NTB, Special Issue, Systems for monitoring deformation and gas pollution control based on the technology of sensor networks, № 128, p.p. 56-70, (2013).

11. M. Belova, E. Iakovleva, A. Popov, Journal of Ecological Engineering, Mining and environmental monitoring at open-pit mineral deposits, 20 (5), p.p. 172-178, (2019)

12. E.V. Iakovleva, M.V. Belova, A.L. Popov, Proceedings of the 2019 IEEE Conference of Russian Young Researchers in Electrical and Electronic Engineering, ElConRus, Study of the magnetic permeability of mountain rocks based on the comprehensive analysis of the pulsed electromagnetic field parameters, № 8657009, pp. 859-863, (2019).

13. Guidelines for the safe conduct of mining operations in the fields of Gornaya Shoriya, prone and dangerous for mining shocks. Novokuznetsk, 75 p., (2001).

14. K.V. Morozov, St. Petersburg Mining University. Proceedings of the V-VI International Scientific and Practical Conference «Innovative areas in the design of mining enterprises» Automated system for underground deformation monitoring of the rock mass of the Glubokiy mine of JSC PPGHO, p.p. 320-324, (2017). 
15. A.G. Protosenya, M.A. Karasev, N.A. Belyakov, Journal of Mining Science Elastoplastic problem for noncircular openings under Coulomb's criterion, №1 p.p. 71-81, (2016). 